\title{
Application of a pig ligated intestinal loop model for early Lawsonia intracellularis infection
}

Torsten S Boutrup ${ }^{1,2}$, Kirsten Schauser $^{3}$, Jørgen S Agerholm², Tim K Jensen ${ }^{1 *}$

\begin{abstract}
Background: Porcine proliferative enteropathy in pigs is caused by the obligate, intracellular bacterium Lawsonia intracellularis. In vitro studies have shown close bacterium-cell interaction followed by cellular uptake of the bacterium within $3 \mathrm{~h}$ post inoculation (PI). However, knowledge of the initial in vivo interaction between porcine intestinal epithelium and the bacterium is limited. The aims of the present study were to evaluate the usefulness of a ligated small intestinal loop model to study L. intracellularis infections and to obtain information on the very early L. intracellularis-enterocyte interactions.
\end{abstract}

Methods: A ligated small intestinal loop model using three different L. intracellularis inocula was applied to 10-11week-old pigs. The inocula were 1) wild type bacteria derived from overnight incubation of L. intracellularis bacteria from spontaneous disease, 2) crude vaccine bacteria (Enterisol ${ }^{\circledR}$ lleitis Vet), and 3) vaccine bacteria propagated in cell culture. The bacteria-enterocyte interaction was visualised using immunohistochemistry on specimens derived 1, 3 and 6 h PI respectively.

Results: Although at a low level, close contact between bacteria and the enterocyte brush border including intracellular uptake of bacteria in mature enterocytes was seen at 3 and $6 \mathrm{~h}$ PI for the vaccine and the propagated vaccine inocula. Interaction between the wild-type bacteria and villus enterocytes was scarce and only seen at $6 \mathrm{~h}$ $\mathrm{PI}$, where a few bacteria were found in close contact with the brush border.

Conclusions: The ligated intestinal loop model was useful with respect to maintaining an intact intestinal morphology for up to $6 \mathrm{~h}$. Furthermore, the study demonstrated that L. intracellularis interacts with villus enterocytes within 3 to $6 \mathrm{~h}$ after inoculation into intestinal loops and that the bacterium, as shown for the vaccine bacteria, propagated as well as non-propagated, was able to invade mature enterocytes. Thus, the study demonstrates the early intestinal invasion of L. intracellularis in vivo.

\section{Introduction}

The bacterium Lawsonia intracellularis is the infectious cause of proliferative enteropathy (PE) in pigs and a range of other animal species [1,2]. The bacterium is Gram negative, rod-shaped and belonging to the delta division of the Proteobacteria. Bacterial growth requires an intracellular environment and in vitro isolation and cultivation depends on cell culture [3]. The successful isolation and growth of the bacterium in vitro has established the basis for vaccine development $[4,5]$. Knowledge on the initial host-pathogen interaction in vivo is limited. However in vitro studies have shown close bacterium-cell interaction followed by cellular uptake of the

\footnotetext{
* Correspondence: tije@vet.dtu.dk

${ }^{1}$ National Veterinary Institute, Technical University of Denmark, Bülowsvej 27,
} DK-1790 Copenhagen V, Denmark bacterium within $3 \mathrm{~h}$ post inoculation (PI) [6]. Recently experimental infection of pigs has demonstrated enterocyte-bacterium interaction as early as $12 \mathrm{~h}$ PI [7].

Intestinal loop models have previously demonstrated their usefulness in studies of Brachyspira hyodysenteriae and Salmonella Typhimurium [8-11]. McOrist et al. [12] used ligated intestinal loops to investigate events between $L$. intracellularis and enterocytes at $1 \mathrm{~h}$ PI but found no intracellular uptake of $L$. intracellularis or bacteria-enterocyte interactions. The aims of the present study were to evaluate the usefulness of an intestinal loop model to investigate $L$. intracellularis infections and to obtain information on very early $L$. intracellularis-enterocyte interactions. Compared to the study performed by McOrist et al. [12] the exposure time between $L$. intracellularis and the intestinal epithelium

\section{Biomed Central}


in the loops were extended to 1, 3 and $6 \mathrm{~h}$. Moreover three different preparations of L. intracellularis inoculums were used at each point.

\section{Materials and methods}

Experimental animals

Four pigs were purchased from a high health (specific pathogen free (SPF)) herd considered to be free of $L$. intracellularis infection after a medicated eradication program. Twenty blood samples and 10 faecal samples from pigs with body weights (BW) of 30 to $60 \mathrm{~kg}$ were sampled twice from the herd and tested by ELISA and PCR methods as described elsewhere [13,14] to ensure herd status regarding L. intracellularis infection. All samples tested negative.

The pigs were acclimatised for 2 weeks before entering the study. Clinical signs of disease were not observed during this period. As a precaution, all pigs were medicated with tiamulin at arrival (Tiamutin ${ }^{\circledR}$ vet. $200 \mathrm{mg} / \mathrm{ml}$, Novartis, Copenhagen, Denmark), given at a dosage of $20 \mathrm{mg} / \mathrm{kg} \mathrm{BW}$ intramuscularly for 4 consecutive days. Faecal samples taken before and after medication were all found negative for L. intracellularis by PCR. To avoid adverse effect of the antibiotic treatment on the study, treatment with tiamulin was ceased at least 7 days before inoculation.

The four pigs were housed together and fed a standard diet ad libitum (DLG, +10 , Aarhus, Denmark) with free access to water and straw. The animals were fasted from the day before experimentation with free access to water with glucose added. The pigs were 10-11-weekold (BW 26 to $31 \mathrm{~kg}$ ) at the time of surgery. The experimental study was approved by the Danish Animal Experiments Inspectorate under the Ministry of Justice.

\section{Inoculum \\ Infectious materials derived from spontaneously diseased pigs}

Prior to the trial, porcine small intestines having PE were collected from a herd that had previously delivered infectious materials for successful experimental infections $[7,15]$. The presence of $L$. intracellularis associated with $\mathrm{PE}$ in the material was confirmed by immunofluorescense (IF) using an anti-L. intracellularis monoclonal antibody (Law1-DK) [16,17]. The intestines were frozen at $-80^{\circ} \mathrm{C}$ in portions of $100 \mathrm{~g}$. The day before inoculation, a portion was thawed in a water bath at $37^{\circ} \mathrm{C}$ and epithelial cells were isolated by immersing the material into $100 \mathrm{ml}$ of Hank's balanced salts solution (HBSS) without $\mathrm{CaCl}_{2}$ and $\mathrm{MgCl}_{2}$ (Invitrogen, 14180-046, Taastrup, Denmark) diluted 1:10 in Milli Q water, with $5 \mathrm{mM}$ EDTA (Merck, 15498, Albertslund, Denmark) and incubated at $37^{\circ} \mathrm{C}$ for $80 \mathrm{~min}$ with occasional stirring. Detached epithelial cells and L. intracellularis bacteria were harvested by centrifugation at $5000 \mathrm{~g}$ for $30 \mathrm{~min}$. The cells were resuspended in $100 \mathrm{ml}$ Dulbecco's Modified Eagle medium (DMEM) (Invitrogen, 41965) with 5\% fetal bovine serum (FBS) (Sigma, F9665, Vallensbaek, Denmark), 1\% L-glutamine (Invitrogen, 25030), 2\% amphotericin B (Sigma, A2942), gentamycine $50 \mu \mathrm{g} / \mathrm{ml}$ (Sigma, G3632) and vancomycine $100 \mu \mathrm{g} / \mathrm{ml}$ (Sigma, V2002) and incubated overnight at $37^{\circ} \mathrm{C}$, in an atmosphere of $8.8 \% \mathrm{CO}_{2}$ and $8.0 \% \mathrm{O}_{2}$. Next day the inocula were centrifuged at $5000 \mathrm{~g}$ for $30 \mathrm{~min}$ and resuspended in $50 \mathrm{ml}$ of DMEM with $5 \%$ FBS and the epithelial cells were lysed by forcing the suspension through a 3.5 inch 22 Gauge spinal syringe (Becton Dickinson, 405256, Madrid, Spain). In vitro cell culture inoculations have shown an initial intracellular replication of similar level using this method compared to crude mucosal scraping (data not shown). Compared to crude mucosal scraping, the described method provides rather homogenous inoculum.

\section{Infectious materials derived from commercial $L$. intracellularis live vaccine}

A commercial L. intracellularis live vaccine (Enterisol ${ }^{\circledR}$ Ileitis Vet., No. 024390, Batch no 30496-00) was purchased and held at $5^{\circ} \mathrm{C}$ until use. Immediately before inoculation into intestinal loops $0.8 \mathrm{~g}$ of freeze dried vaccine were dissolved in $5 \mathrm{ml}$ of DMEM with $5 \%$ FBS. This corresponds to four doses according to manufacturer.

Infectious materials derived from commercial $L$. intracellularis live vaccine propagated in cell culture Infected cell cultures based on the $L$. intracellularis vaccine were produced by suspending $0.4 \mathrm{~g}$ of freeze dried vaccine in DMEM with 5\% FBS and 1\% L-glutamine and inoculating the suspension into a McCoy cell culture (ATCC number: CRL-1696), T-80 bottles with 15 $\mathrm{ml}$ medium seeded with $2 \times 10^{5}$ cells per $\mathrm{ml}$ from the day before. The infected cell cultures were incubated at $37^{\circ} \mathrm{C}$, in $8.8 \% \mathrm{CO}_{2}$ and $8.0 \% \mathrm{O}_{2}$. Passage of infection was done by scraping of McCoy cells, which were lysed by forcing the suspension through a 3.5 inch 22 Gauge spinal syringe. Cell debris were removed by centrifugation at $150 \mathrm{~g}$ for $5 \mathrm{~min}$, bacteria were harvested by centrifugation at $5000 \mathrm{~g}$ for $20 \mathrm{~min}$. The bacterial pellet was re-suspended in $3 \mathrm{ml}$ of medium and re-inoculated onto new cell cultures as described above. At the day of inoculation, two cell culture bottles with massive growth of L. intracellularis were used. The cells were scraped from the bottom and lysed as described above. Cells and bacteria were centrifuged at $5000 \mathrm{~g}$ for $20 \mathrm{~min}$, where after the pellet was re-suspended in $10 \mathrm{ml}$ of medium.

The concentration of $L$. intracellularis in the different inocula was determined by serial 1:10 dilutions in sucrose potassium glutamate (SPG) with $5 \%$ FBS. Ten $\mu$ l of each dilution were added to each well in a six-well 
glass slide and examined by indirect IF [16]. The number of $L$. intracellularis bacteria was counted at $40 \times$ objective magnification in 10 view fields corresponding to $1 / 25$ of a well. The concentrations in the different types of inocula are shown in Table 1 . Five $\mathrm{ml}$ of each inoculum was injected into the lumen of intestinal loops via an $18 \mathrm{G}$ syringe.

\section{Anaesthetic and surgical procedure}

Isoflurane inhalation anaesthesia and surgical procedures were done as described by Grøndahl et al. [18] and modified by Shauser et al. [10]. Isotonic saline was administered intravenously throughout the procedure. Pulse, blood pressure, rectal temperature and blood gas pressure were monitored. A midline abdominal incision was made and ten loops were produced in the upper jejunum and lower jejunum, respectively (Table 1 ). The first loop in the lower jejunum was made $10 \mathrm{~cm}$ oral to the ileocaecal orifice with additional nine loops ligated in oral direction. The first upper jejunal loop was made $1 \mathrm{~m}$ oral to the confluent ileal Peyer's patch with additional nine loops ligated in oral direction. Each loop was approximately $5 \mathrm{~cm}$ long followed by an inter-loop segment of around $2 \mathrm{~cm}$. Ligation was done by a intestinal circumferential ligature through the mesentery without damaging grossly visible mesenteric vascular arcades thus maintaining full blood supply for both loops and inter-loop segments. The overall anaesthetic period was 7 to $8 \mathrm{~h}$ where after pigs were euthanised by an overdose of sodium pentobarbital while still anaesthetised.

Loops were inoculated for 1, 3 and $6 \mathrm{~h}$ for each inoculum. Initially four lower jejunal and four upper jejunal

Table 1 Overview of types- and concentrations of inocula used in each ligated intestinal loops.

\begin{tabular}{|c|c|c|c|}
\hline $\begin{array}{l}\text { Loop } \\
\text { No. }\end{array}$ & $\begin{array}{c}\text { Inoculation } \\
\text { time }\end{array}$ & Inoculation type & $\begin{array}{c}\text { Inoculum } \\
\text { concentration }\end{array}$ \\
\hline 1 & & Wild-type & $4-6 \times 10^{8}$ bacteria $/ \mathrm{ml}$ \\
\hline 2 & & Live vaccine & $3-5 \times 10^{6}$ bacteria $/ \mathrm{ml}$ \\
\hline 3 & & $\begin{array}{l}\text { Propagated live } \\
\text { vaccine }\end{array}$ & $2-8 \times 10^{7}$ bacteria $/ \mathrm{ml}$ \\
\hline 4 & & Negative control & Mock inoculum \\
\hline 5 & & Wild-type & $4-6 \times 10^{8}$ bacteria $/ \mathrm{ml}$ \\
\hline 6 & & Live vaccine & 3- $5 \times 10^{6}$ bacteria $/ \mathrm{m}$ \\
\hline 7 & & $\begin{array}{l}\text { Propagated live } \\
\text { vaccine }\end{array}$ & $2-8 \times 10^{7}$ bacteria $/ \mathrm{ml}$ \\
\hline 8 & & Wild-type & $4-6 \times 10^{8}$ bacteria $/ \mathrm{ml}$ \\
\hline 9 & & Live vaccine & $3-5 \times 10^{6}$ bacteria $/ \mathrm{ml}$ \\
\hline 10 & & $\begin{array}{l}\text { Propagated live } \\
\text { vaccine }\end{array}$ & $2-8 \times 10^{7}$ bacteria $/ \mathrm{ml}$ \\
\hline
\end{tabular}

Ligation of ten loops (1-10) was done in the ileum and the jejunum, respectively. All three types of inocula applied were exposed for 1, 3 and $6 \mathrm{~h}$, while only at $6 \mathrm{~h}$ a negative control was included (loop No. 4). The

concentration of Lawsonia intracellularis in the inocula is shown in the table; 5 $\mathrm{ml}$ of inoculum were used for each loop. loops were made (Table 1). One loop served as negative control and were inoculated with DMEM with 5\% FBS, one loop was inoculated with the wild-type bacterial suspension, one with vaccine suspension and one with the suspension of cell culture propagated vaccine. This procedure was repeated after $3 \mathrm{~h}$ and again after $5 \mathrm{~h}$, but without control loops (Table 1). Inter-loop segments served as non-inoculated controls at 3 and $5 \mathrm{~h}$.

\section{Tissue processing}

The loops were sampled at euthanasia by cutting the mesentery and immediately cooled on thawing ice. The ends of each loop were cut off, the lumen was rinsed with isotonic saline and the tissues were fixed in $10 \%$ neutral buffered formalin for 24 to $48 \mathrm{~h}$. The tissue was cut into transverse sections, exposed to graded series of alcohol succeeded by xylene and embedded in paraffin.

\section{Immunohistochemistry}

The loop specimens, each consisting of two full cross sections, were cut in $5 \mu \mathrm{m}$ thick sections and mounted on Super Frost*/plus slides (Menzel-Gläser, Braunschweig, Germany). Mounted slides were heated to $60^{\circ} \mathrm{C}$, deparaffinised and rehydrated in xylene, graded series of alcohol and finally in water. Endogenous peroxidase activity was inhibited by incubation with $0.6 \% \mathrm{H}_{2} \mathrm{O}_{2}$ in tris buffered saline (TBS) $(50 \mathrm{mM}$ Tris, $150 \mathrm{mM} \mathrm{NaCl}$, $\mathrm{pH}$ 7.6) for $20 \mathrm{~min}$ followed by washing in TBS $3 \times 5$ min. Slides were incubated with $0.05 \%$ protease (Sigma, type XXIV, 8038) in TBS for $10 \mathrm{~min}$ followed by washing in TBS $3 \times 5 \mathrm{~min}$. Slides were incubated $1 \mathrm{~h}$ with polyclonal rabbit anti L. intracellularis antibody [7] diluted 1:10000 in TBS, washed for $3 \times 5 \mathrm{~min}$ in TBS and incubated with Envision ${ }^{+}$goat anti-rabbit conjungate (DAKO, K4002, Glostrup, Denmark). After washing for $3 \times 5 \mathrm{~min}$ in TBS, reaction was developed for $15 \mathrm{~min}$ with a solution of 3-amino-9-ethylcarbozole (AEC) (Kementec, 4190, Copenhagen, Denmark) followed by washing in TBS $3 \times 5 \mathrm{~min}$, counterstained by Mayer's haematoxylin and mounted with glycergel (DAKO, C563). All procedures were undertaken at a room temperature around $20^{\circ} \mathrm{C}$.

\section{Microscopic evaluation}

Slides were evaluated by light microscopy using $40 \times$ and $63 \times$ objectives. In tissue from mock inoculated loops and inter-loop segments, absence of L. intracellularis antigens were evaluated for both intestinal lumen and mucosa.

In inoculated loops the presence of intracellular bacteria was evaluated, including a specific search for bacteria in the brush border with no free space in between enterocytes and the bacterium (Figure $1 \mathrm{C}$ and 1D). The presence of $L$. intracellularis antigen in the intestinal 

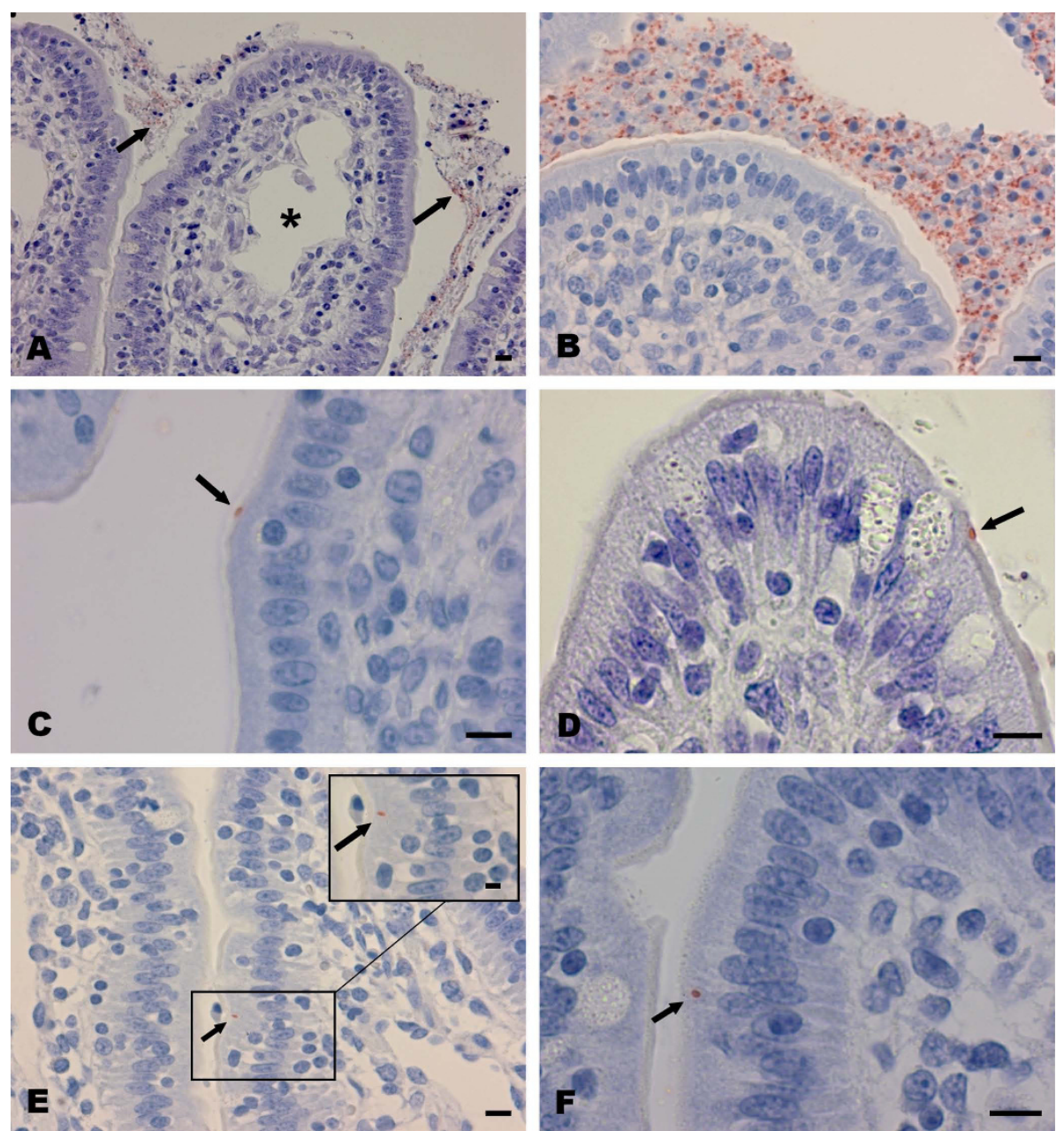

Figure 1 Visualisation of Lawsonia intracellularis in tissue of inoculated intestinal loops. Immunohistochemistry/haematoxylin stain of Lawsonia intracellularis in intestinal tissue; arrows point at immunopositive red stained L. intracellularis. A and B: Bacteria overlying ileal epithelium $6 \mathrm{~h}$ post inoculation (PI). A) Vaccine derived inoculum. B) Wild-type derived inoculum. In both (A) and (B) close interactions between bacteria and enterocytes is not found. Low level oedema seen as distended central lacteal (A) (asterisk). C and D: Solitary L. intracellularis bacteria in intimate contact with the brush border of enterocytes $6 \mathrm{~h} \mathrm{PI}$. C) Vaccine derived inoculum in jejunal loop. D) Cell culture propagated vaccine in ileal loop. E and F: Solitary intracellular L. intracellularis bacteria in villus enterocytes $6 \mathrm{~h} \mathrm{PI}$. E) Vaccine derived inoculum in jejunal loop. F) Cell culture propagated vaccine in ileal loop. Insert in (E) shows a higher magnification of the area with the intracellular bacterium. Bars: $10 \mu \mathrm{m}$.

lumen and mucus overlying villus epithelium and in the crypts was noted but considered as a passive presence due to inoculation.

\section{Results}

Ligation was found to induce grossly visible local mesenteric oedema and decreased intestinal wall tonus. Pallor of the intestinal wall indicating inadequate blood supply did not occur, congestion of mesentery and intestinal vessels remained at a low level and mild stromal oedema was the only histologically circulatory associated lesion (Figure 1A). Together these findings indicate a limited negative impact on the intestinal blood supply due to the procedures applied. In general the rectal temperature was slowly decreased from around $37.5^{\circ} \mathrm{C}$ to $36.2^{\circ} \mathrm{C}$, although one pig had a terminal rectal temperature of $35.8^{\circ} \mathrm{C}$. One pig had a mild local chronic adhesive fibrous peritonitis. L. intracellularis antigen was not found by IHC in the negative control loops or in the inter-loop segments.

Although only a few bacteria were seen in direct contact with enterocytes or the brush border during the first $6 \mathrm{~h}$ PI for all types of inocula, differences were observed as bacteria of the vaccine inoculum and vaccine propagated inoculum seemed to be in direct contact with the mucosa more frequently than the wild type. Bacteria were seen as single distinct organisms within in the brush border of the villus enterocytes $3 \mathrm{~h}$ and $6 \mathrm{~h}$ PI (Figures 1C and 1D). The number of bacteria in direct contact with the brush border varied but 
mostly 10-25 organisms per full transverse intestinal section were seen. In addition, single intracellular L. intracellularis bacteria (1-5 organisms per intestinal cross section) were found in villus enterocytes $6 \mathrm{~h}$ PI (Figures $1 \mathrm{E}$ and $1 \mathrm{~F}$ ) indicating a low level infection. By contrast, only 5-10 L. intracellularis bacteria of the wild type were seen in close proximity to the brush border for loops inoculated for $6 \mathrm{~h}$ but not for loops inoculated for 1 or $3 \mathrm{~h}$. Wild type intracellular bacteria were not observed at all.

Interaction between bacteria and crypt epithelium was not observed irrespectively of type of inoculum. However, IHC demonstrated that the inoculated material had remained in the lumen.

\section{Discussion}

The study demonstrates that mature enterocytes are infected by L. intracellularis thus, confirming previous studies examining the bacterium-enterocyte interaction during later stages of infection. In a recent study by Boutrup et al. [7]L. intracellularis was demonstrated in villus enterocytes $12 \mathrm{~h}$ PI in pigs inoculated by stomach tube with a mucosal scraping obtained from pigs naturally affected by PE. Whether $L$. intracellularis is able to propagate in the mature amitotic enterocytes is however not known. Interestingly, invasion was only shown for vaccine derived $L$. intracellularis, cell culture propagated as well as non-propagated. Interaction between bacteria and mucosa was observed at 3 and $6 \mathrm{~h}$ PI. Similar to the study by McOrist et al. [12] based on a modified intestinal loop model inoculated with a laboratory attenuated strain of L. intracellularis, we did not observe interaction between bacteria and enterocytes $1 \mathrm{~h}$ PI. It could be postulated that the observed interaction occurred just by chance, i.e. that some bacteria passively adhered to the brush border. However, if that had been the case we would have expected such a phenomenon to occur randomly in all loops. We did not see close interaction at all $1 \mathrm{~h}$ PI despite the type of inoculum. Furthermore, differences were observed among inocula as the wild type showed less interaction than the vaccine regarding both the number of interacting bacteria and interaction $3 \mathrm{~h}$ PI. This indicates that interaction was not an accidental event.

Direct evidence for specific target cells during the initial exposure of the intestinal epithelium to L. intracellularis has not been shown. However, data from experimental studies [19-22] on the location and events of L. intracellularis infection from $24 \mathrm{~h}$ to $3 \mathrm{wks}$ in hamsters and pigs report the presence of intracellular bacteria and the development of hyperplastic lesions as taking place from infected crypt cells. Also some authors propose the crypt cells to be the target cell population for L. intracellularis [23,24]. Bacterial invasion of crypt enterocytes was not observed in this study. However, this may be due to retention of the inoculum above the crypt-villus junction.

The ligated intestinal loop model has previously shown its usefulness in studies of intestinal bacterial infections [8-11]. The validity of the model highly depends on conservation of a normal intestinal function and environment. Our study shows that the model seems useful with respect to maintaining an intact intestinal morphology as the only histomorphological change in the intestinal mucosa seen after ligation of intestinal loops for up to $6 \mathrm{~h}$ was a slight stromal oedema. As lethal or sublethal changes, as e.g. hydrophic degeneration or enhanced exfoliation of enterocytes, did not occur, we suggest that the intestinal barrier remained intact and mimicked the epithelium of a nonligated intestine. However, we cannot exclude the presence of ultrastructural changes of e.g. the cytoskeleton, which might play a role for uptake of bacteria and intracellular replication [25]. However, the model may have several pitfalls. The uneven distribution of the inoculum may indicate an impaired intestinal motility. Also the intestinal microenvironment may have been influenced as a $5 \mathrm{ml}$ inoculum was injected into ligated segments thus arresting normally occurring bacteria and their metabolic products in a confined space. Although not being associated with significant lesions, the ligation may have affected vasculature and nerves causing a change in e.g., $\mathrm{pH}$ and oxygen tension in the microenvironment. It cannot be excluded that such physical and/or chemical changes may have affected the properties of L. intracellularis. The low level of infection is however surprising, especially because a well established infection is established no later than $12 \mathrm{~h}$ PI of infectious material by stomach tube [7] and because the bacteria were in active growth as observed by direct microscopy of cell cultures. The causes remain speculative. The microenvironment may have been unfavourable for both bacteria and enterocytes as discussed previously e.g. the course of an infection with $L$. intracellularis depends on feeding strategies $[15,26,27]$ indicating an importance of intestinal microenvironment on the bacteria. Also the bypassing of the stomach may have influenced the pathogenic potential of the bacteria.

The observed patterns of localisation for the wild-type and vaccine derived $L$. intracellularis differed as the wild-type seemed less infective than the vaccine. This is surprising as the wild-type was supposed to be more virulent. The difference may be due to the procedures used for isolation of the wild-type bacteria. For example, HBBS/EDTA treatment or the addition of antibiotics to the growth medium may have impeded the wild-type. Therefore, this study can not be used for comparison of virulence but only to study the early pathogenesis. 
Based on several experiments, it is our experience that induction of clinical disease (diarrhoea, loss of weight and extensive proliferative lesions) following oral inoculation with $L$. intracellularis in pigs older than 6-8 weeks is difficult. This observation is supported by Mapother et al. [28], which produced severe gross lesions in pigs weighing around $7 \mathrm{~kg}$ but only mild lesions in larger pigs weighing around 55 and $90 \mathrm{~kg}$. The pigs used in the present study were 10-11-week-old at the time of the surgical procedure. Even though others have reported the induction of experimental infection in pigs being 10- week-old [29] or older [30], we believe that an additional study using younger pigs should be performed to evaluate whether this could increase the magnitude of bacteria-enterocyte interaction, and thereby the usefulness of the model.

\section{Conclusions}

The study shows that as early as 3 to $6 \mathrm{~h}$ after inoculation into intestinal loops, L. intracellularis interacts with villus epithelium resulting in subsequent uptake in mature enterocytes. Furthermore, this study shows the usefulness of a pig ligated intestinal loop model as an alternative to in vitro models in investigating early bacteria-host cells interactions in L. intracellularis infections. However the limited number of bacteria seen in close association with or intracellular in enterocytes limits the models usefulness with regard to investigating factors enhancing or blocking cellular uptake.

\section{Acknowledgements \\ The excellent technical assistance of Annie Ravn Pedersen, Dennis Schultz Jensen and Hanne Hornemann Møller is gratefully appreciated.}

\section{Author details \\ 'National Veterinary Institute, Technical University of Denmark, Bülowsvej 27, DK-1790 Copenhagen V, Denmark. ${ }^{2}$ Department of Veterinary Disease Biology, Faculty of Life Sciences, University of Copenhagen, Ridebanevej 3, DK-1870 Frederiksberg C, Denmark. ${ }^{3}$ Department of Basic Animal and Veterinary Sciences, Faculty of Life Sciences, University of Copenhagen, Grønnegårdsvej 7, DK-1870 Frederiksberg C, Denmark.}

\section{Authors' contributions}

TSB designed the study, prepared the inoculum, performed the surgical procedures, sampled materials, did the initial histopathological and immunohistochemical evaluations, participated in interpretation of results and drafted the manuscript. KS participated in designing the study and participated in the surgical procedures and drafting of the manuscript. JSA and TKJ participated in designing the study, interpretation of results and drafting of the manuscript. All authors read and approved the final manuscript.

\section{Competing interests}

The authors declare that they have no competing interests.

Received: 3 November 2009 Accepted: 24 February 2010 Published: 24 February 2010
References

1. McOrist S, Gebhart CJ, Boid R, Barns SM: Characterization of Lawsonia intracellularis gen. nov., sp. nov., the obligately intracellular bacterium of porcine proliferative enteropathy. Int J Syst Bacteriol 1995, 45:820-825.

2. Lawson GHK, Gebhart CJ: Proliferative enteropathy. J Comp Pathol 2000, 122:77-100.

3. Lawson GHK, McOrist S, Jasni S, Mackie RA: Intracellular bacteria of porcine proliferative enteropathy: cultivation and maintenance in vitro. $J$ Clin Microbiol 1993, 31:1136-1142.

4. Guedes RBC, Gebhart CJ: Onset and duration of fecal shedding, cellmediated and humoral immune responses in pigs after challenge with a pathogenic isolate or attenuated vaccine strain of Lawsonia intracellularis. Vet Micobiol 2003, 91:135-145.

5. Kroll JJ, Roof MB, McOrist S: Evaluation of protective immunity in pigs following oral administration of an avirulent live vaccine of Lawsonia intracellularis. Am J Vet Res 2004, 65:559-565.

6. McOrist S, Jasni S, Mackie RA: Entry of the bacterium ileal symbiont itracellularis into cultured enterocytes and its subsequent release. Res Vet Sci 1995, 59:255-60.

7. Boutrup TS, Boesen HT, Boye M, Agerholm JS, Jensen TK: Early pathogenesis in porcine proliferative enteropathy caused by Lawsonia intracellularis . J Comp Pathol .

8. Hughes R, Olander HJ, Williams CB: Swine dysentery: Pathogenecity of Treponema hyodysenteriae. Am J Vet Res 1975, 36:971-977.

9. Whipp SC, Harris DL, Kinyon JM, Songer JG, Glock RD: Enteropathogenicity testing of Treponema hyodysenteriae in ligated colonic loops of swine. Am J Vet Res 1978, 39:1293-1296.

10. Schauser K, Olsen JE, Larsson L: Immunocytochemical studies of Salmonella Typhimurium invasion of porcine jejunal epithelial cells. $J$ Med Microbiol 2004, 53:691-695.

11. Schauser K, Olsen JE, Larsson L: Salmonella Typhimurium infection in the porcine intestine: evidence for caspase-3-dependent and -independent programmed cell death. Histo Chem Cell Biol 2005, 123:43-50.

12. McOrist S, Gebhardt CJ, Bosworth BT: Evaluation of porcine ileum models of enterocyte infection by Lawsonia intracellularis. Can J Vet Res 2006, 70:155-159.

13. Boesen HT, Jensen TK, Møller K, Nielsen LH, Jungersen G: Evaluation of a novel enzyme-linked immunosorbent assay for serological diagnosis of porcine proliferative enteropathy. Vet Microbiol 2005, 109:105-112.

14. Lindecrona RH, Jensen TK, Andersen PH, Møller K: Application of a 5' nuclease assay for detection of Lawsonia intracellularis in fecal samples from pigs. J Clin Microbiol 2002, 40:984-987.

15. Boesen HT, Jensen TK, Schmidt AS, Jensen BB, Jensen SM, Møller K: The influence of diet on Lawsonia intracellularis colonization in pigs upon experimental challenge. Vet Microbiol 2004, 103:35-45.

16. Jensen TK, Møller K, Leser TD, Jorsal SE: Comparison of histology, immunohistochemistry and polymerase chain reaction for detection of Lawsonia intracellularis in natural porcine proliferative enteropathy. Eur J Vet Pathol 1997, 3:115-123.

17. Boesen HT, Jensen TK, Jungersen G, Riber U, Boye M, Møller K: Development, characterization and diagnostic application of a monoclonal antibody specific for a proteinase $\mathrm{K}$ resistant Lawsonia intracellularis antigen. Vet Microbiol 2005, 105:199-206.

18. Grøndahl ML, Jensen GM, Nielsen CG, Skadhauge E, Olsen JE, Hansen MB: Secretory pathways in Salmonella Typhimurium-induced fluid accumulated in the porcine small intestine. J Med Microbiol 1998, 47:151-157.

19. Frisk CS, Wagner JE: Experimental hamster enteritis: An electron microscopic study. Am J Vet Res 1977, 38:1861-1868.

20. Jasni S, McOrist S, Lawson GHK: Experimentally induced proliferative enteritis in hamsters: an ultrastructural study. Res Vet Sci 1994, 56:186-192.

21. Johnson EA, Jacoby RO: Transmissible ileal hyperplasia of hamsters II. Ultrastructure. Am J Pathol 1978, 91:451-468.

22. McOrist S, Lawson GHK, Rowland AC, Maclntyre N: Early lesions of proliferative enteritis in pigs and hamsters. Vet Pathol 1989, 26:260-264.

23. Smith DGE, Lawson GHK: Lawsonia intracellularis : getting inside the pathogenesis of proliferative enteropathy. Vet Microbiol 2001, 82:331-345.

24. Lawson GHK, Gebhart CJ: Proliferative enteropathy. J Comp Path 2000, 122:77-100. 
25. Lawson GHK, Mackie RA, Smith DGE, McOrist S: Infection of cultured rat enterocytes by lleal symbiont intracellularis depends on host cell function and actin polymerisation. Vet Microbiol 1995, 45:339-350.

26. Stege $H$, Jensen TK, Møller K, Bækbo P, Jorsal SE: Risk factors for intestinal pathogens in Danish finishing pig herds. Prev Vet Med 2001, 50:153-164.

27. Mølbak L, Johnsen K, Boye M, Jensen TK, Johansen M, Møller K, Leser TD: The microbiota of pigs influenced by diet texture and severity of Lawsonia intracellularis infection. Vet Microbiol 2008, 128:96-107.

28. Mapother ME, Joens LA, Glock RD: Experimental reproduction of porcine proliferative enteritis. Vet Rec 1987, 121:533-36.

29. Collins AM, Love RJ: Re-challenge of pigs following recovery from proliferative enteropathy. Vet Microbiol 2007, 120:381-386.

30. Rowland AC, Rowntree PGM: A haemorrhagic bowel syndrome associated with intestinal adenomatosis in the pig. Vet Rec 1972, 91:235-41.

doi:10.1186/1751-0147-52-17

Cite this article as: Boutrup et al: Application of a pig ligated intestinal loop model for early Lawsonia intracellularis infection. Acta Veterinaria Scandinavica 2010 52:17.

\section{Submit your next manuscript to BioMed Central} and take full advantage of:

- Convenient online submission

- Thorough peer review

- No space constraints or color figure charges

- Immediate publication on acceptance

- Inclusion in PubMed, CAS, Scopus and Google Scholar

- Research which is freely available for redistribution

Submit your manuscript at www.biomedcentral.com/submit
C Biomed Central 